\title{
A Wide Load Range and High Efficiency Switched-Capacitor DC-DC Converter With Pseudo-Clock Controlled Load-dependent Frequency
}

\author{
Wei-Chung Chen, Student Member, IEEE, Da-Long Ming, Yi-Ping Su, Yu-Huei Lee, and \\ Ke-Horng Chen, Senior Member, IEEE
}

\begin{abstract}
A high efficiency 3.3 V-to-1 V switched-capacitor (SC) step-down DC-DC converter with load-dependent frequency control (LFC) and deep-green mode (DGM) operation is proposed for system-on-a-chip (SoC) application. According to output loading current, the LFC technique can immediately and dynamically adjust the switching frequency through the use of pseudo-clock generator (PCG) and lead-lag detector (LLD) circuit to obtain high power conversion efficiency and small output voltage ripple over a wide loading current range. Therefore, adequate loading current supplying function and output voltage regulation can be guaranteed. Moreover, the DGM operation, similar to pulse skipping mode, can mask the switching clock to reduce power loss at ultralight loads for further improving power efficiency. The test chip fabricated in $55 \mathrm{~nm}$ CMOS process demonstrates that the proposed fast transient converter can deliver wide load range from $10 \mathrm{~mA}$ to $250 \mathrm{~mA}$ with two small flying capacitors $\left(C_{F 1}, C_{F 2}=\right.$ $0.1 \mu \mathrm{F})$ and one output capacitor $\left(C_{\mathrm{OUT}}=1 \mu \mathrm{F}\right)$. The peak conversion efficiency is $89 \%$ compared to the ideal value of $91 \%$ $\left(3 * V_{\mathrm{OUT}} / V_{\mathrm{IN}}\right)$. In other words, the peak normalized efficiency is equal to $98 \%$. The overall normalized efficiency is always kept higher than $90 \%$ while the output voltage ripple is guaranteed smaller than $30 \mathrm{mV}$.
\end{abstract}

Index Terms-Deep-green mode (DGM), lead-lag detector (LLD), load-dependent frequency control (LFC), pseudo-clock generator (PCG), switched-capacitor (SC), system-on-a-chip (SoC).

\section{INTRODUCTION}

I N RECENT years, power management units are widely used in portable devices such as smart phones, notebooks, PDAs, cameras, etc. The characteristic of high power conversion efficiency and fully integration in system-on-chip ( $\mathrm{SoC})$ for a compact size is the main design goal in power management module. To provide the supply current over a wide load range, the inductor-based switching DC-DC converter is commonly used in $\mathrm{SoC}$ applications [1]. However, due to large occupation of print-circuit-board (PCB) area and high cost resulted from the usage of inductor, it is hard to further reduce the size of power management module especially for SoC system applications. Furthermore, electromagnetic interference (EMI), which is easily derived when using the magnetic components, often becomes the thorny issue in the $\mathrm{SoC}$ applications.

SC DC-DC converter has the features of small size, simple control scheme, and the moderate power conversion efficiency

Manuscript received March 18, 2013; revised May 30, 2013; accepted August 10, 2013. Date of publication October 28, 2013; date of current version February 21, 2014. This paper was recommended by Associate Editor S. Chattopadhyay.

The authors are with the Institute of Electrical Control Engineering, National Chiao Tung University, Hsinchu 30010, Taiwan.

Color versions of one or more of the figures in this paper are available online at http://ieeexplore.ieee.org.

Digital Object Identifier 10.1109/TCSI.2013.2284182

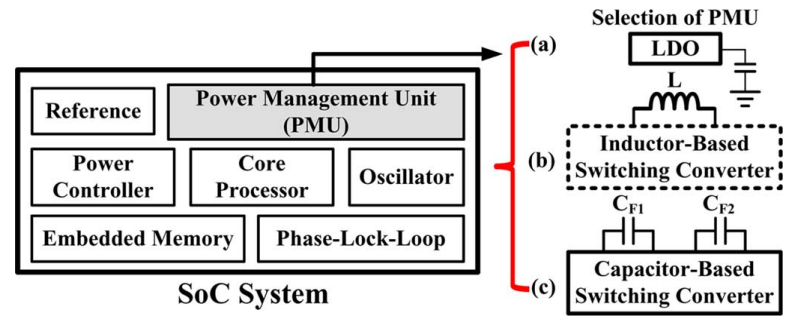

Fig. 1. Illustration of the power management in SoC applications.

[2]-[6]. Fig. 1 shows the SoC application with power management unit. Owing to the advantages of small size and low cost in SC DC-DC converter, the capacitor-based switching converter is a good candidate of power management compared to the inductor-based power management. Both step-down and step-up operations can be realized through the combination of different energy delivery paths along with the distinct connections of the flying capacitors [7]-[9]. In addition, to achieve the supply function in SoC applications, the closed-loop operation of the SC DC-DC converter must be activated to derive a well-regulated output voltage [10], [11]. To replace conventional inductor-based switching regulator by the SC converter, the driving capability and power conversion efficiency are important design issues because the power supplies are necessary to provide the SoC over a wide load range. Many control schemes have been provided to improve the overall efficiency of DC-DC converters [12]-[16]. However, prior arts are realized with large inductors or flying capacitors.

Furthermore, fully integrated SC converter with on-chip flying and output capacitors, which can be the replacement of low-dropout (LDO) regulator in some applications, has limited load current range within several mili-amperes [17]. Besides, on-chip capacitance suffers from serious parasitic capacitances and limited silicon area since the cost for the on-chip capacitance is very high in advanced process. Moreover, if small flying capacitors and output capacitor are used, the operating frequency should be increased to ensure the driving capability. In other words, the disadvantages of on-chip capacitance are large switching loss and low flexibility.

For the designs fabricated in nanometer advanced process, it's necessary to provide core devices a regulated $1 \mathrm{~V}$ supply voltage [17], [18]. If the input voltage $V_{\mathrm{IN}}$ ranges from $3.3 \mathrm{~V}-3.6 \mathrm{~V}$ and the output voltage $V_{\text {OUT }}$ is $1 \mathrm{~V}$, the conversion ratio can be designed as $1 / 2 \mathrm{x}$ or $1 / 3 \mathrm{x}$ without considering any no-ideal loss. Conventional SC DC-DC architecture is shown in Fig. 2(a) to drive wide loading current range with small flying capacitors at a fixed switching frequency [19]. As illustrated in Fig. 2(b), the output voltage almost looses the regulation at the point $\mathrm{A}$ 


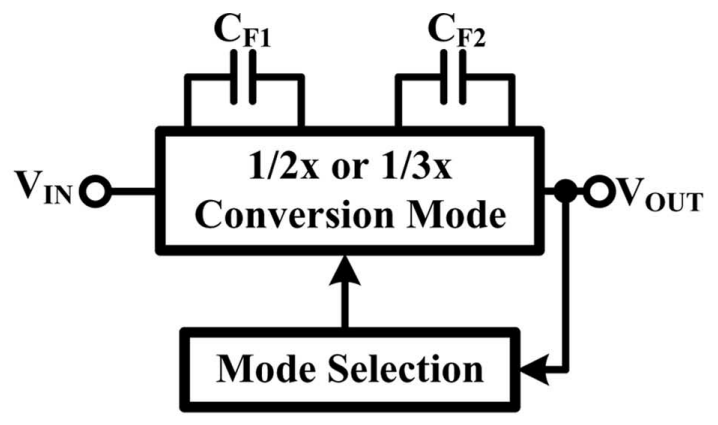

Conversional SC Architecture

(a)

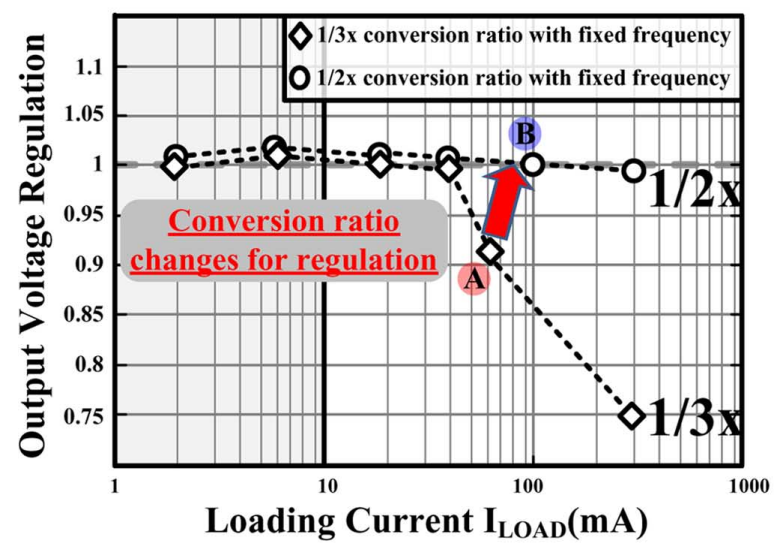

(b)

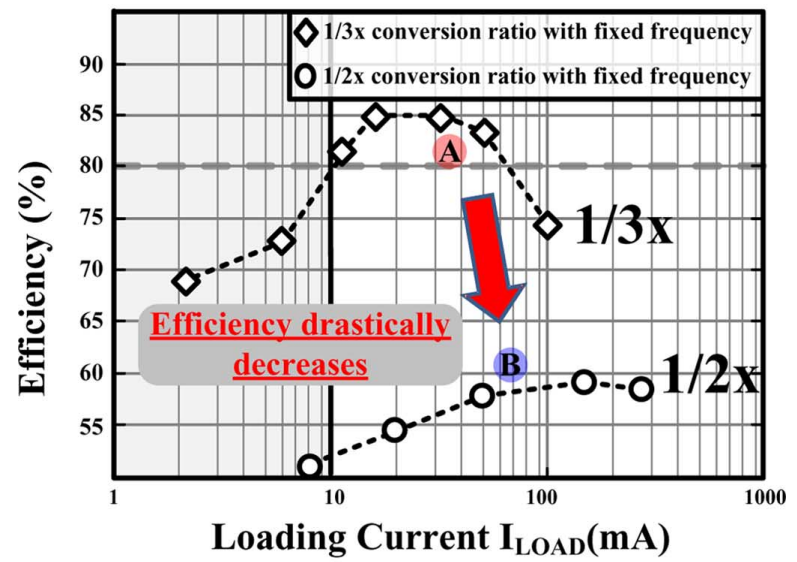

(c)

Fig. 2. (a) Conversional SC architecture. (b) Output voltage regulation vs. loading current. (c) Efficiency vs. loading current.

because of the insufficient current driving capability at heavy loads if $1 / 3 x$ conversion ratio is utilized. To achieve high current driving capability and to regulate the output voltage, the controller can change the conversion ratio from $1 / 3 x$ to $1 / 2 x$. That is, the operation point is moved from point A to point $\mathrm{B}$. Although the output voltage remains regulated at heavy loads, the power efficiency will be largely reduced to an unacceptable value because $1 / 2 x$ conversion ratio suffers much extra power loss compared to the 1/3x operation as illustrated in Fig. 2(c).

Consequently, one alternative way is to increase the switching frequency in the proposed design for supplying large output power and maintaining output regulation. As illustrated in Fig.

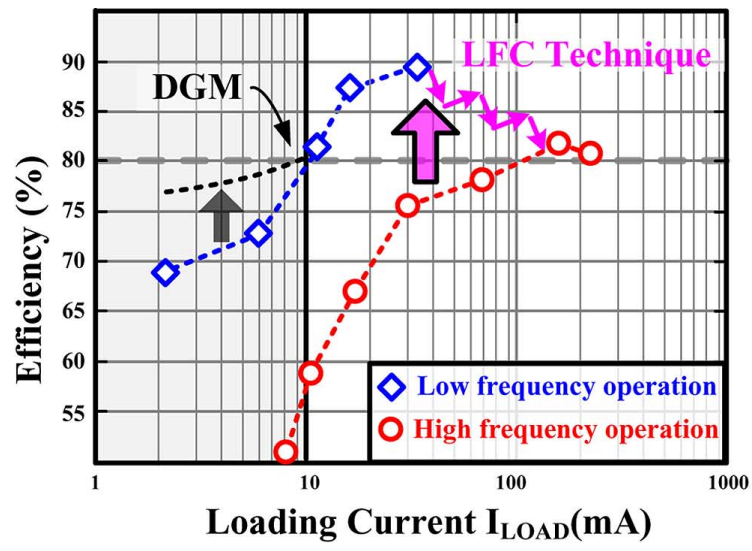

(a)

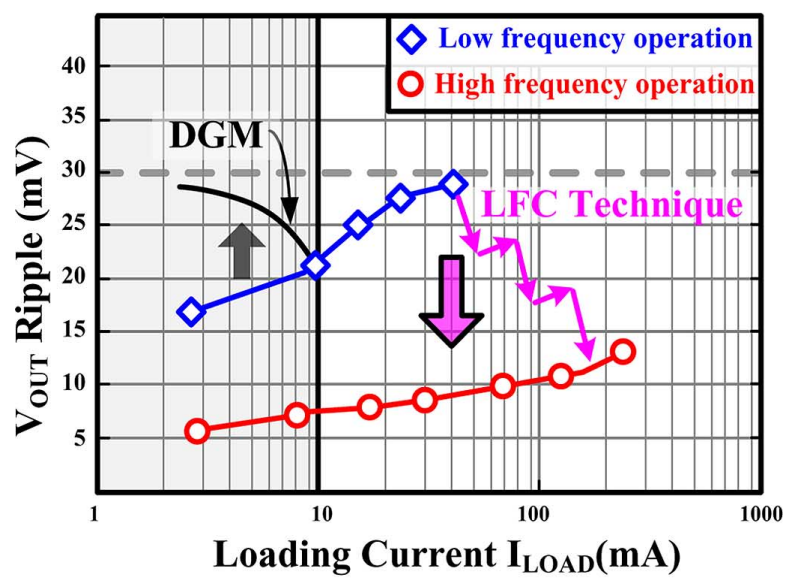

(b)

Fig. 3. Design target of power conversion efficiency in (a) and the output voltage ripple in (b) of the proposed SC DC-DC converter.

3(a), the lower switching frequencies used in SC DC-DC converter contributes lower power loss and thus benefits higher power conversion efficiency. However, energy supplementation is limited by low switching frequencies. That is to say, load range is restricted because of insufficient energy to output at heavy loads. In contrast, the output voltage ripple will be reduced by increasing the frequency as shown in Fig. 3(b) and the output regulation can be guaranteed. Therefore, the load-dependent frequency control (LFC) technique with the deep-green mode (DGM) operation are realized in the proposed SC DC-DC converter to derive an adequate power conversion efficiency and obtain a satisfactory output voltage ripple over a wide load range. According to specific load condition, the proposed LFC technique, which contains pseudo-clock generator (PCG) and lead-lag detector (LLD) circuit, can modulate the switching frequency to obtain an optimum energy supply distribution. Furthermore, the LFC technique can gradually adjust the switching frequency in order to avoid large drop in power conversion efficiency.

In order to further improve efficiency at ultra-light loads, the DGM operation takes over the operation by deeply reducing the switching frequency at the sacrifice of the output ripple. By monitoring the output energy, the controller is activated to transfer energy to the output once it requires energy and consequently reduces power loss. In other words, the controller stays at idle stage for saving energy and the trade-off between efficiency and output ripple happens in the DGM operation. As 


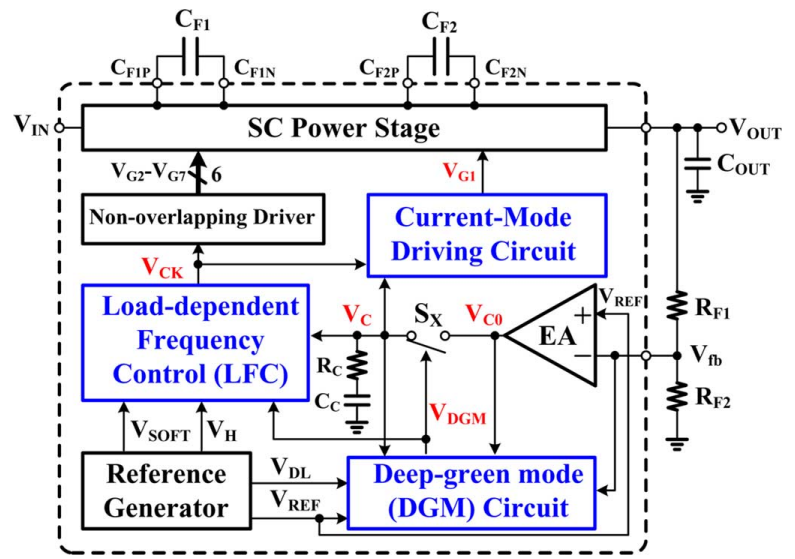

Fig. 4. Proposed SC DC-DC converter with the LFC technique and the DGM circuit.

a result, the performance of both power efficiency and output voltage ripple can be simultaneously guaranteed within a satisfactory range at distinct output load conditions for SoC applications.

The proposed SC DC-DC converter structure is illustrated in Section II. Circuit implementations are described in Section III. Experimental results are shown in Section IV. Finally, a conclusion is made in Section V.

\section{Proposed SC DC-DC Converter Structure AND STABILITY ANALYSIS}

Fig. 4 shows the proposed SC DC-DC converter structure with two small off-chip flying capacitors, $C_{F 1}$ and $C_{F 2}$, to deliver the energy from the input $V_{\text {IN }}$ to the output $V_{\text {OUT }}$. To regulate the $V_{\text {OUT }}$ and to ensure supplying quality for the other circuits in SoC, the voltage divider, composed of $R_{F 1}$ and $R_{F 2}$, is used to feedback the output information. Feedback signal $V_{f b}$ compares with the reference voltage $V_{\mathrm{REF}}$ by the error amplifier (EA) to generate the pre-error signal $V_{C 0}$. Through the closedloop operation in normal operation, the error signal $V_{C}$ connecting to $V_{C 0}$ with the switch $S_{X}$ can decide the charging time of the flying capacitor and the level of the analog signal $V_{G 1}$ to define the driving capability of SC power stage. Therefore, loading current dependent energy control scheme in SC power stage can be realized [20]. The closed-loop control simply uses the proportional-integral (PI) compensation composed of $R_{C}$ and $C_{C}$ to generate a low-frequency pole-zero pair to increase system stability.

Due to the loading information contained by the $V_{C}$ in normal operation, the proposed LFC technique can monitor the trend of loading current during load transient response. Besides, the slope of $V_{C}$ represents the trend of load condition and is used to generate the system clock $V_{\mathrm{CK}}$ for controlling the switching frequency $f_{\mathrm{CK}}$, which represents the switching frequency. The system performance is improved by a trade-off between switching power loss and output voltage ripple.

In other words, the proposed pseudo-clock controlled LFC technique dynamically adjusts the switching frequency according to the trend of different load condition. When the loading current increases toward heavy condition, the LFC technique gradually increases the $f_{\mathrm{CK}}$ to provide high current driving capability and to ensure regulation performance. Moreover, the output ripple can be reduced by meanings of increasing $f_{\mathrm{CK}}$. On the other hand, when the loading current suddenly decreases, the LFC technique will accordingly decrease the

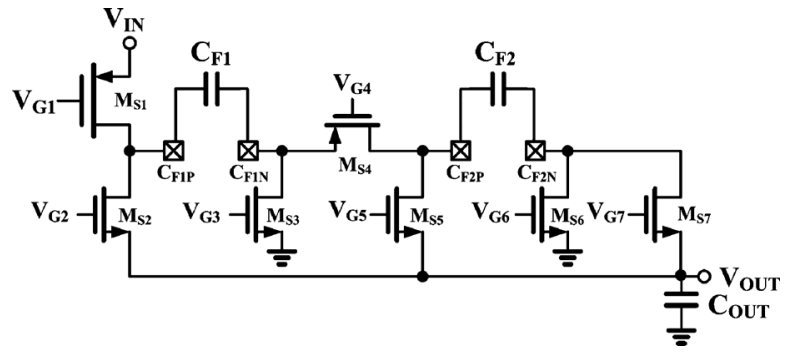

Fig. 5. Implementation of SC power stage.

$f_{\mathrm{CK}}$ for high efficiency because of reduced switching power loss. Besides, the switching frequency changing between the four operating frequencies $(0.5,1,2$, and $4 \mathrm{MHz})$ can instantly provide driving current to the output for good load transient performance. It also brings the advantage of reduced EMI to meet the requirement of the SoC. Moreover, the LFC technique uses the reference voltage $V_{H}$ and the $V_{\mathrm{SOFT}}$, derived from the reference generator, to calibrate the switching frequency in normal operation and to provide soft-start operation for high reliability in startup period.

On the other hand, the DGM operation is activated at ultralight loads to effectively enhance power conversion energy if the $V_{C 0}$ is smaller than the signal reference voltage $V_{\mathrm{DL}}$. In the meanwhile, the DGM circuit triggers the signal $V_{\mathrm{DGM}}$, which masks the switching clock until the output demands for energy replenishment. The $V_{\mathrm{DGM}}$ also turns off the $S_{X}$ and clamps the $V_{C}$ to prevent the cross interference between the normal operation and the DGM operation. In other words, the controller works as a ripple-based control by monitoring output voltage. Furthermore, power conversion efficiency is also guaranteed by the non-overlapping driver, which generates the six-bit signals $V_{G 2}-V_{G 7}$ to have enough current driving capability and to avoid the shoot through current.

\section{A. SC Power Stage}

Fig. 5 illustrates the $\mathrm{SC}$ power stage, which contains seven power switches to realize $1 / 3 \mathrm{x}$ conversion ratio. The transistor $M_{S 1}$ is used as a current source to control the charging current to the flying capacitors while the other transistors work as the power switched. Here, the duty of switching period is fixed as $50 \%$. Basically, the ideal power conversion efficiency is shown as (1).

$$
\eta_{\max }=\frac{1}{M} \times \frac{V_{\mathrm{OUT}}}{V_{\mathrm{IN}}}
$$

Due to the step-down operation in the proposed SC converter, the power conversion efficiency is mainly decided by the relationship between the input voltage $V_{\text {IN }}$, the output voltage $V_{\text {OUT }}$ and the conversion ratio $M$, which is $1 / 3$ in this work.

The simplified dc model of SC converter with the current-mode driving control is depicted in Fig. 6. Corresponding to the $1 / 3 \mathrm{x}$ SC power stage, it includes the dependent voltage source $M V_{\mathrm{IN}}$, the adjusting equivalent resistance $R_{1}$, the output loading $R_{\mathrm{LOAD}}$, and output capacitor $C_{\mathrm{OUT}}$. The equivalent function contributed by the transistors $M_{S 2}-M_{S 7}$ is modeled as an equivalent voltage source with a conversion ration $M$. The transistor $M_{S 1}$ in SC power stage can work as an adjustable $R_{1}$ because $M_{S 1}$ can control the charging energy by adjusting the gate voltage $V_{G 1}$, which is derived from the current-mode driving circuit. This simplified de model doesn't contain the conduction loss, switching loss and the quiescent 


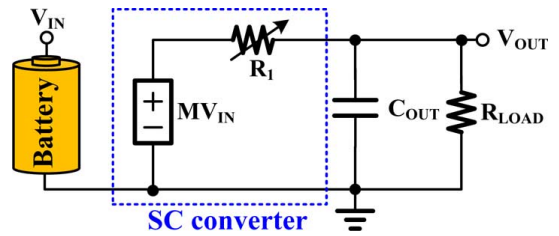

Fig. 6. Simplified de model of the SC power stage with the current-mode driving control.

current loss. Thus, the output voltage can be regulated as a predefined voltage by adjusting the $R_{1}$ as expressed in (2). If the $V_{\text {OUT }}$ is far away from the value of $M V_{\text {IN }}$ due to the increasing loading current $I_{\mathrm{LOAD}}$, the efficiency will become lower than (1) because large power loss occurs in the voltage drop across the adjustable $R_{1}$.

$$
V_{\mathrm{OUT}}=M \times V_{\mathrm{IN}}-I_{\mathrm{LOAD}} \times R_{1}
$$

The energy charging and discharging schemes of the SC power stage are illustrated in Figs. 7(a) and (c), respectively. During energy charging phase, the charging current directly flows from the $V_{\mathrm{IN}}$ to the $V_{\mathrm{OUT}}$ through two flying capacitors $C_{F 1}$ and $C_{F 2}$. According to different load current, the charging current is controlled by the gate control signal $V_{G 1}$. The remaining power switches are operated with the driving signals $V_{G 2}-V_{G 7}$ from the non-overlapping driver to provide correct energy discharging phase. During the energy discharging phase, both the flying capacitors are in parallel connected to the output capacitor for providing enough driving current.

To derive the power loss of the SC converter, Fig. 7(b) and (d) depict the model, which includes the on-resistance of power switch $R_{S}$ and the ESR of the flying capacitors, in charging phase and discharging phase, respectively. The period of the charging or discharging phase is half of the switching cycle because the duty cycle is fixed at 50\%. In Fig. 7(b) and (d), the $I_{\mathrm{LOAD}}$ is equal to the $I_{\text {charge }}$ in the charging phase while the $I_{\mathrm{LOAD}}$ is equal to twice the $I_{\text {discharge }}$ in the discharging phase.

Total power loss as shown in (3) includes conduction power loss $P_{\mathrm{CON}+\mathrm{ESR}}$, switching power loss $P_{\text {switching }}$, and extra

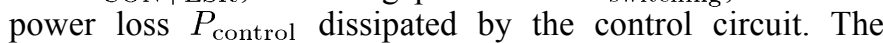
$P_{C O N+E S R}$ in (4) is resulted by the power transistors and the ESR. The $P_{\text {switching }}$ is caused by charging and discharging the parasitic capacitance parallel to each flying capacitor as expressed in (5).

$$
\begin{aligned}
P_{\text {total }} & =P_{\mathrm{CON}+\mathrm{ESR}}+P_{\text {switching }}+P_{\text {control }} \\
P_{\mathrm{CON}+\mathrm{ESR}} & =I_{\mathrm{LOAD}}^{2}\left(1.5 R_{S}+1.25 \mathrm{ESR}+0.5 R_{1}\right) \\
P_{\text {swithcing }} & =\frac{1}{2} f_{\mathrm{CK}} \times \sum_{i=1}^{2} C_{\mathrm{par} \_i} \times \Delta V_{\mathrm{par} \_i}^{2}
\end{aligned}
$$

where $C_{\text {par } \_i}$ is the parallel parasitic capacitance of the $i$-th flying capacitor and $\Delta V_{p a r \_i}$ is the voltage difference within half of one switching period.

When the system operates at light loads, the total power loss is mainly dominated by the $P_{\text {switching. That is to say, the } P_{\text {switching }}}$ can be further reduced if the switching frequency $f_{\mathrm{CK}}$ is properly adjusted by the proposed LFC technique. As a result, the efficiency can be effectively improved especially at light and medium loads. Furthermore, small flying capacitor can be used

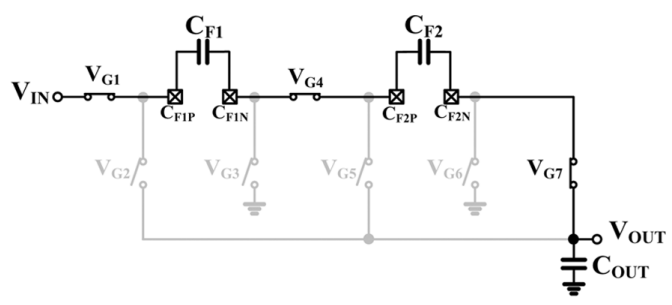

(a)

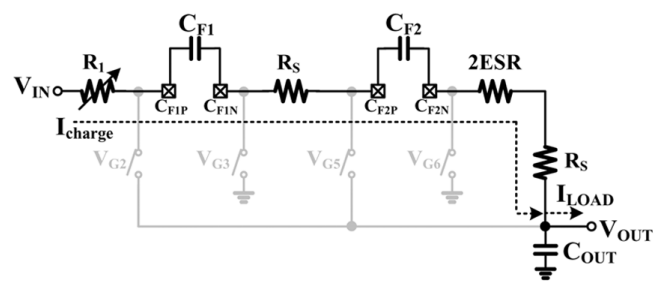

(b)

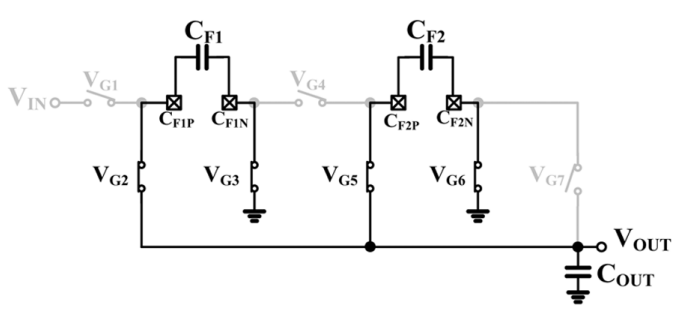

(c)

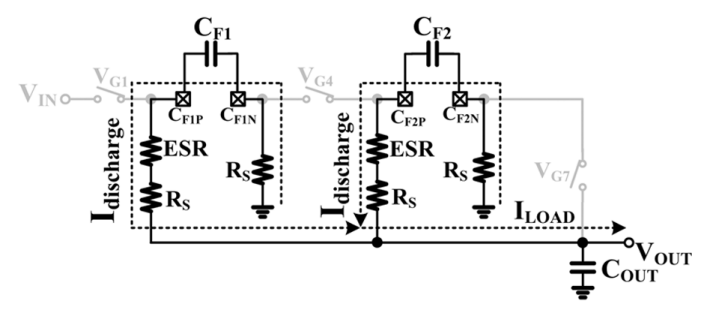

(d)

Fig. 7. (a) Operation in the charging phase. (b) Modeling including conduction loss and ESR resistors in the charging phase. (c) Operation in the discharging phase. (d) Modeling including conduction loss and ESR resistors in the discharging phase.

because the $f_{\mathrm{CK}}$ can be changed according to the loading current. Consequently, the $P_{\mathrm{CON}+\mathrm{ESR}}$ caused by the ESR can also be reduced since small flying capacitor accompanies a small ESR. In conclusion, the LFC technique changes the switching frequency according to the loading current can enhance the efficiency.

\section{B. Pseudo-Clock Controlled LFC Operation}

The main purpose of LFC technique is to immediately adjust the switching frequency for achieving adequate energy driving capability, high efficiency, and fast transient response for different loading current. The output voltage information $V_{f b}$ is delivered to the EA from the voltage divider, $R_{F 1}$ and $R_{F 2}$ as shown in Fig. 4. Thus, the output of the EA, $V_{C 0}$, reflects the loading current information. In the normal operation, $V_{C}$ shorts to $V_{C 0}$ by turning $S_{X}$. Considering the stability, PI compensator, composed of compensation resistor $R_{C}$ and capacitor $C_{C}$, is adopted to extend the bandwidth and low-frequency gain for regulation performance. In steady state, the $V_{C}$ is regulated at one certain voltage level. In case of loading current transient, the driving current capability of power stage will be changed 


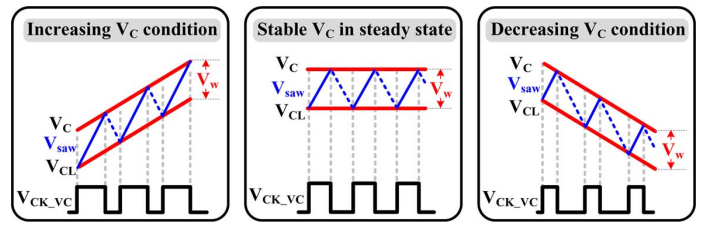

Fig. 8. The pseudo-clock $V_{\mathrm{CK}-\mathrm{VC}}$ under different trend of the $V_{C}$ in LFC technique.

TABLE I

THE ILLUSTRATION OF RELATIONSHIP BETWEEN $V_{C}$ AND $V_{\mathrm{CK}-\mathrm{VC}}$

\begin{tabular}{|c|c|c|c|}
\hline $\mathrm{V}_{\mathrm{C}}$ - condition & \multicolumn{2}{|c|}{ Pseudo-clcok $\mathrm{V}_{\mathrm{CK}_{-} \mathrm{VC}}$} & Duty cycle \\
\hline Stable & & & \\
\hline Increasing & & & $\mathrm{D}=\mathbf{5 0} \%$ \\
\hline Decreasing & & $\mathrm{D}>50 \%$ \\
\hline
\end{tabular}

by the variation of $V_{C}$. Interestingly, the trend of the $V_{C}$ variation can be used to indicate the proper trend in the variation of switching frequency.

As depicted in Fig. 8, the signal $V_{\mathrm{CK}_{-} \mathrm{VC}}$ is defined as a pseudo-clock, which is generated by a saw-tooth signal $V_{\text {saw }}$ ramping up/down within a pre-defined fixed hysteresis window $V_{W} \cdot V_{C}$ is the upper bound of the hysteresis window. Besides, in steady state, the duty cycle of $V_{\mathrm{CK}-\mathrm{VC}}$ is $50 \%$. With a fixed hysteresis window, $V_{W}$, the trend of the $V_{C}$ variation can vary the duty of $V_{\mathrm{CK}_{-} \mathrm{VC}}$. In case of light-to-heavy load change, the increasing $V_{C}$ forces the duty of $V_{\mathrm{CK}-\mathrm{VC}}$ to be larger than $50 \%$ since the on-time increases and the off-time decreases. On the other hand, the heavy-to-light loads change forces the duty of $V_{\mathrm{CK} \_\mathrm{VC}}$ smaller than $50 \%$. Consequently, according to the trend of the $V_{C}$ variation, the difference of $V_{\mathrm{CK}-\mathrm{VC}}$ is listed in Table I. In other words, wider range of load transient which makes larger voltage variation at the output results in larger duty variation of the $V_{\mathrm{CK} \_\mathrm{VC}}$.

To obtain adequate energy driving capability by adjusting the switching frequency, the $V_{\mathrm{CK}_{-} \mathrm{VC}}$ should compare with one pre-defined reference-clock $V_{C K \_R E F}$ to decide the increase or decrease in the switching frequency as illustrated in Fig. 9. Similarly, the duty of $V_{C K_{-} R E F}$ is fixed at 0.5 . Thus, the $V_{C K_{-} R E F}$ synchronizes with the $V_{\mathrm{CK}-\mathrm{VC}}$ in steady state. One threshold period $t_{T H}$ is utilized to avoid oscillation between two different switching frequencies in the LFC technique. In case of light-to-heavy loads change, the duty of $V_{\mathrm{CK}_{-} \mathrm{VC}}$ is larger than 0.5 . If the variation of duty is larger than the value of $t_{\mathrm{TH}}$, the switching frequency will be increased. As depicted in Fig. 9(a), the $V_{\mathrm{CK}}$ is increased to a higher value. In other words, the light-to-heavy loads change causes the increase of $V_{C}$ and thus makes the $V_{\mathrm{CK}_{-} \mathrm{VC}}$ lags the $V_{C K_{-} R E F}$ with the amount of lagging period $t_{L A G}$ since the current switching frequency can't have the ability to deliver enough energy to the output. After the increase of switching frequency by the LFC technique, the $\mathrm{SC}$ converter can provide adequate energy to the output. Meanwhile, the $V_{C K_{-} R E F}$ will synchronize with the $V_{\mathrm{CK}_{-} \mathrm{VC}}$ again after the output voltage is regulated.

On the other hand, if the loads change from heavy to light, the phase of $V_{\mathrm{CK}_{-} \mathrm{VC}}$ leads that of $V_{C_{K} \_R E F}$. As shown in Fig. 9(b), when the leading time $t_{L E A D}$ is larger than the $t_{T H}$, the switching frequency should be decreased to avoid excess energy

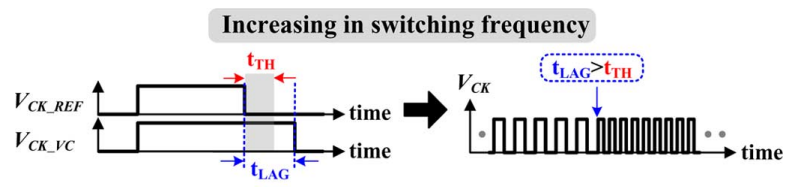

(a)

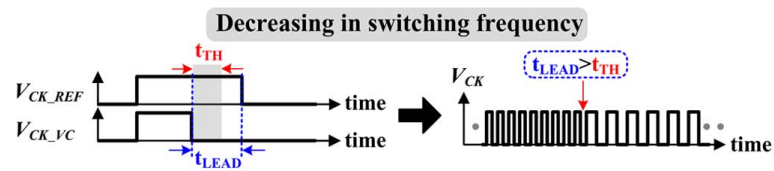

(b)

Fig. 9. Comparison of $V_{C K_{-} V C}$ and $V_{C K_{-} R E F}$ in LFC technique for (a) increasing and (b) decreasing in switching frequency.

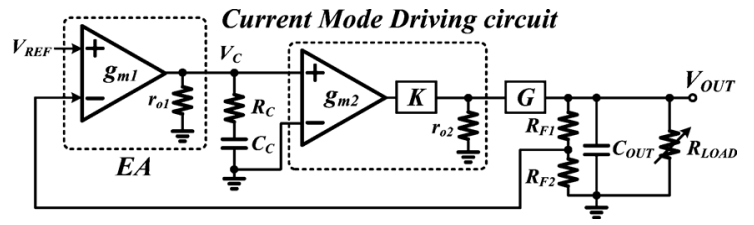

Fig. 10. Small signal model of the proposed SC converter.

delivering to the output. After the adjustment in the switching frequency by the LFC technique, the output voltage will be wellregulated and the $V_{C K_{-} R E F}$ will synchronize with the $V_{\mathrm{CK}_{-} \mathrm{VC}}$. In conclusion, the proposed pseudo-clock controlled technique reflects the load conditions and the LFC technique features the fast transient response owing to the adjustable switching frequency according to different duty of $V_{\mathrm{CK}-\mathrm{VC}}$ and $V_{C K_{-} R E F}$. Furthermore, the $\mathrm{SC}$ converter operates with a proper switching frequency for adequate energy driving capability in steady state.

\section{System Stability Analysis}

The small signal model of the SC converter with the PI compensation, which is composed of the resistor $R_{C}$ and the capacitor $C_{C}$, is illustrated in Fig. $10 . \mathrm{K}$ is defined as the gain of current-mode driving circuit. $\mathrm{G}$ is defined as the gain of power stage of SC converter. The ideal value of $\mathrm{G}$ is equal to $1 / 3$ according to the structure of the switches and flying capacitors. Two poles as expressed in (6) and (7) locate at the output of EA and the output $V_{\text {OUT }}$, respectively.

$$
\begin{aligned}
\omega_{p 1} & =\frac{1}{C_{C}\left(r_{o 1}+R_{C}\right)} \\
\omega_{p 2} & =\frac{1}{C_{\mathrm{OUT}} R_{\mathrm{LOAD}}}
\end{aligned}
$$

$r_{o 1}$ is the equivalent output resistance of the EA and $R_{\mathrm{LOAD}}$ is the equivalent loading resistance. Besides, one compensated zero contributed by the PI compensation is shown in (8).

$$
\omega_{z}=\frac{1}{C_{C} R_{C}}
$$

The current-mode driving control circuit converts the $V_{C}$ to the $V_{G 1}$ to control the charging current for charging the flying capacitors. Thus, it's modeled as the combination of the V-I converter $\left(g_{m 2}\right)$ and the current buffer $(K)$, which has an equivalent output resistance $r_{o 2}$. Therefore, the transfer function of SC converter can be expressed in (9).

$$
T(s)=\frac{K g m_{1} r_{o 1} g m_{2}\left(r_{o 2} / / R_{\mathrm{LOAD}}\right)\left(1+s C_{C} R_{C}\right)}{\left(1+s C_{C}\left(r_{o 1}+R_{C}\right)\right)\left(1+s C_{\mathrm{OUT}} R_{\mathrm{LOAD}}\right)}
$$




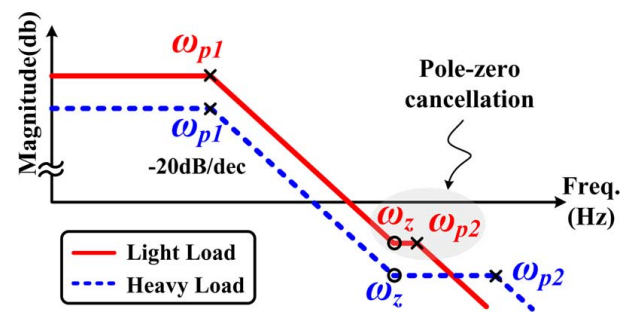

Fig. 11. Frequency response of the proposed SC converter.

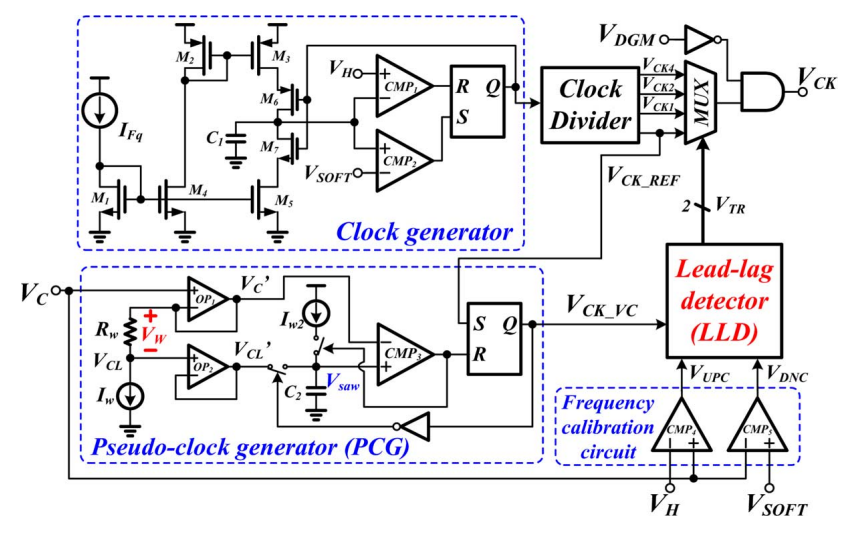

Fig. 12. Schematic of the proposed of LFC circuit.

The frequency response of proposed SC converter is shown in Fig. 11. Because the output pole depends on the load condition, the compensated zero in (8) cancels the lower-frequency output pole at light loads to ensure a sufficiency phase margin (PM). Thus, the pole at the output of EA becomes the dominant pole of the SC converter. Before the unit-gain frequency (UGF), the system simply contains one pole to ensure the stability in the proposed SC converter.

\section{CirCUIT IMPLEMENTATION}

\section{A. Load-Dependent Frequency Control (LFC) Circuit}

Fig. 12 shows the implementation of LFC circuit. To achieve adequate energy driving capability for different output load, the switching frequency in the proposed SC converter can be varied, so as to ensure regulation performance and conversion efficiency. The LFC circuit contains the clock generator, the pseudo-clock generator (PCG), the lead-lag detector (LLD), and the frequency calibration circuit.

The clock generator defines the basic clock and the clock divider produces several clock signals with same duty ratio as $50 \%$ but with different frequencies. The lowest frequency of these signals, $V_{C K_{-} R E F}$, is used as a reference-clock. The system-clock $V_{\mathrm{CK}}$ is adjustable which is controlled by the LLD circuit to increase or decrease the switching frequency when the loading current increases or decreases, respectively. Furthermore, the $V_{\mathrm{CK}}$ can be further modulated by the signal $V_{\mathrm{DGM}}$ for drastically decreasing switching power loss at ultra-light loads.

The $V_{C}$ is connected to the PCG in order to generate the pseudo-clock $V_{\mathrm{CK}_{-} \mathrm{VC}}$ with the variable duty cycle corresponding to the trend of $V_{C}$. In the PCG circuit, the hysteresis window, $V_{W}$, is generated by a fixed DC offset formed by the $I_{W}$ flowing through the resistor $R_{W}$. The upper and the lower bounds are $V_{C}$ and $V_{C L}$, respectively. Two operational amplifiers, $\mathrm{OP}_{1}$ and $\mathrm{OP}_{2}$, are used as the buffer to filter out high frequency noise and to get clean control signals $V_{C}^{\prime}$ and
$V_{C L}^{\prime}$. Here, the determination of the on-time of $V_{\mathrm{CK}_{-} \mathrm{VC}}$ is to compare the saw-tooth $V_{\text {saw }}$, which is generated by charging the capacitor $C_{2}$ with a constant current $I_{W 2}$, with the upper bound, $V_{C}^{\prime}$. On the other hand, the duration of the off-time is decided by the positive edge of the $V_{C K_{-} R E F}$ and $V_{\text {saw }}$ follows $V_{C L}^{\prime}$ (the buffered output of $V_{C L}$ ). Thus, the LLD circuit can decide the lead or lag condition in Fig. 9 to decrease or increase the switching frequency, respectively, by comparing the $V_{\mathrm{CK} \_\mathrm{VC}}$ with the $V_{C K_{-} R E F}$. After the increment or decrement of the switching frequency, the $V_{C K_{-} R E F}$ can synchronize the $V_{\mathrm{CK} \_\mathrm{VC}}$ at the steady state.

The frequency calibration circuit is composed of two comparators, $\mathrm{CMP}_{4}$ and $\mathrm{CMP}_{5}$, which are used to compare the $V_{C}$ with the reference voltage $V_{H}$ and $V_{\mathrm{SOFT}}$, respectively. If the $V_{C}$ approaches the $V_{D D}$ in case of increasing loading current, the gain of the EA is deteriorated because the transistors at the output stage of the EA are in the triode region. Thus, a signal $V_{U P C}$ triggered by frequency calibration circuit to the LLD circuit can avoid the failure of the EA by the increase of switching frequency. That is to say, higher switching frequency ensures higher driving capability and has the ability to pull low the level of the $V_{C}$ until it's within the range of $V_{H}$ and $V_{\mathrm{SOFT}}$. Similarly, if $V_{C}$ approaches the voltage level of $V_{\text {SOFT }}$ in case of decreasing loads, the frequency calibration circuit triggers the $V_{D N C}$ to the LLD circuit to decrease the switching frequency. Here, $V_{\mathrm{SOFT}}$ with a lower voltage level works as the function soft-start to prevent the output from being overcharged by much energy injection, which results in drastic variation at the $V_{C}$ if the output voltage is much lower than its nominal value during start-up period. Namely, the comparison between the $V_{C}$ with the $V_{\text {SOFT }}$ can decide the signal of $V_{D N C}$ to inhibit the switching frequency increasing.

The LLD circuit implementation is depicted in Fig. 13. To avoid abnormal oscillation between two switching frequencies, the threshold period $t_{T H}$ is designed in the LLD circuit. The $t_{T H}$ is determined by the biasing current $I_{\mathrm{BIAS}}$, the capacitor $C_{1}$, and the $V_{\mathrm{REF}}$. When the leading or lagging time of $V_{\mathrm{CK} \_\mathrm{VC}}$ is greater than the $t_{T H}$ compared to the $V_{C K_{-} R E F}$, the signal of $D N$ or the $U P$ will be triggered by the logic circuit to activate the up/down(U/D) counter. Furthermore, when the error signal $V_{C}$ is failed to generate the slope because its level is near the power supply or ground, the frequency calibration signals $V_{U P C}$ and $V_{D N C}$ from the frequency calibration circuit can also trigger the $\mathrm{U} / \mathrm{D}$ counter. Finally, the voltage $V_{T R}$ will be an adequate value in steady state to control the multiplexer which determines the switching frequency of $V_{\mathrm{CK}}$. The time diagram of the LLD circuit is shown in Fig. 14. When the $V_{\mathrm{CK}_{-} \mathrm{VC}}$ lags the $V_{C K_{-}} R E F$, the signal $V_{X}$ ramps up by a constant current and compares with the reference voltage $V_{\mathrm{REF}}$, which determines the $t_{T H}$. Once the lagging time is larger than the $t_{T H}$, the signal UP is sent to increase the switching frequency. Similarly, the switching frequency can be decreased by the signal $D N$ if the leading time is larger than the $t_{T H}$.

Fig. 15 illustrates the detail time diagram in the pseudo-clock controlled LFC technique by the LLD circuit. When the loading current changes, the error signal $V_{C}$ will be varied to response to it by the negative feedback control. Different load steps result in different $V_{C}$ variations and the changes in the duty of $V_{\mathrm{CK}_{-} \mathrm{VC}}$ which is realized by the PCG. It's indicated as mentioned in Table I. Then, the comparison of the $V_{C K_{-} R E F}$ and the $V_{\mathrm{CK}_{-} \mathrm{VC}}$ is implemented in the LLD circuit to determine the adequate frequency by controlling $V_{T R}$. When the loads changes from light to heavy, the duty of $V_{\mathrm{CK}_{-} \mathrm{VC}}$ is larger than the duty of 


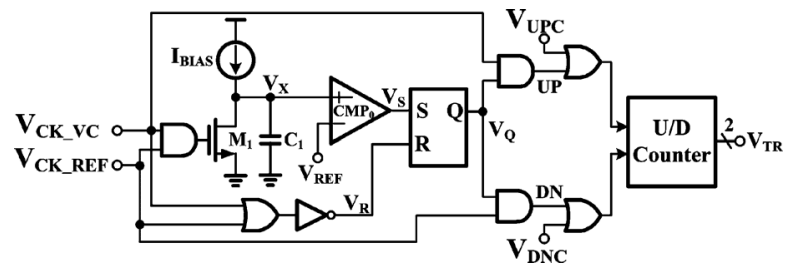

Fig. 13. Schematic of the proposed LLD circuit.

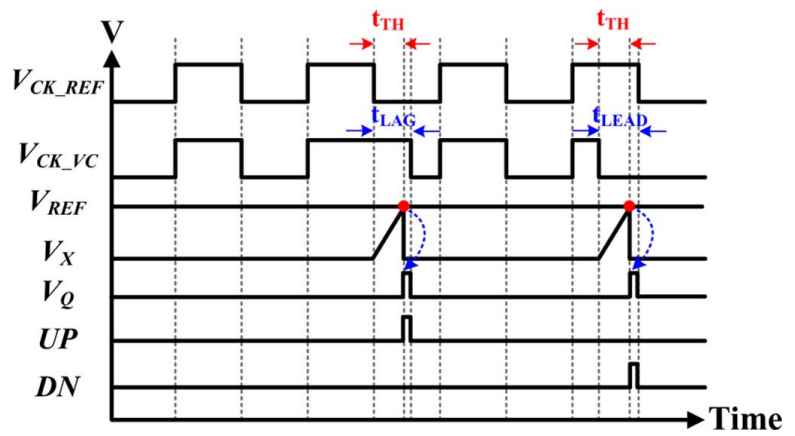

Fig. 14. Time diagram of the LLD circuit.

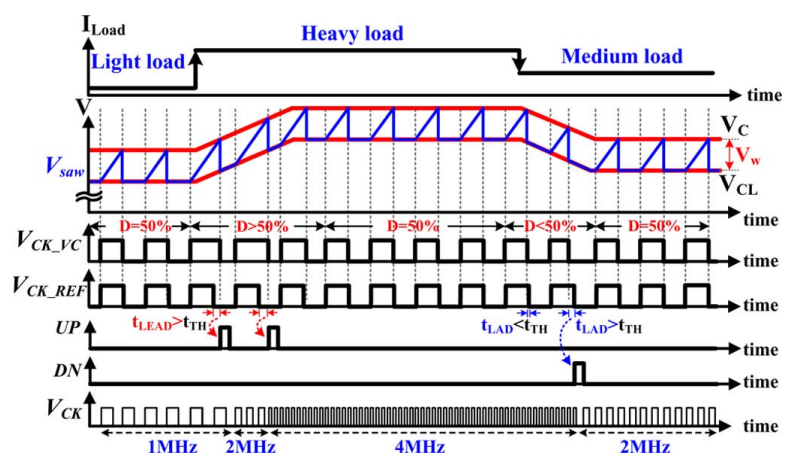

Fig. 15. Time diagram in the pseudo-clock controlled LFC technique by the LLD circuit.

$V_{C K_{-} R E F}$ by the extra period $t_{L A G}$. When the $t_{L A G}$ is longer than the $t_{T H}$, insufficient energy supply derived at the output will result in the increment of switching frequency to guarantee a well-regulated output voltage. That is, the signal UP will be set as logic high to activate the U/D counter. Therefore, the $V_{T R}$ will be increased to select the higher switching frequencies as $V_{\mathrm{CK}}$ until enough energy can be transferred to the output. On the other hand, the decreasing switching frequency will happen when the phase of $V_{\mathrm{CK}_{-} \mathrm{VC}}$ leads that of $V_{C K_{-} R E F}$ higher than the value of $t_{T H}$ in case of heavy-to-light loads.

\section{B. Current-Mode Driving Circuit}

Fig. 16 shows the current-mode driving circuit to drive the power switch $M_{S 1}$ for controlling the energy driving scheme of the proposed SC converter. The error signal $V_{C}$ can be utilized to determine how large the driving current can be sourced from the $M_{S 1}$ since the $V_{C}$ derived from the output of EA contains the load information. The $I_{C R}$ transferred from $V_{C}$ through V-I conversion will be magnified through the three-stage cascaded current mirrors to guarantee the demanded current driving capability. The advantage is the $M_{S 1}$ can be regarded as the current source with small voltage headroom requirement at the energy charging phase. On the other hand, the signal $V_{\mathrm{CK}}$ generated by the LFC circuit will turn off the $M_{S 1}$ to stop the energy charging for the flying capacitor when the SC converter operates at the discharging phase. Moreover, another advantage is that

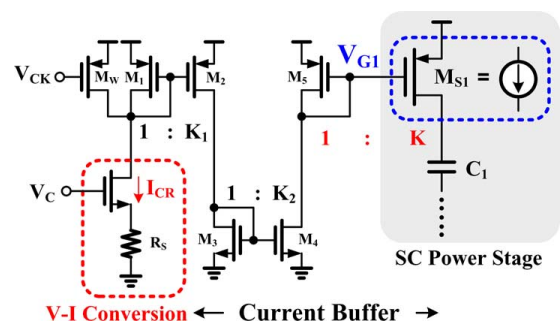

Fig. 16. Schematic of the proposed current-mode driving circuit.

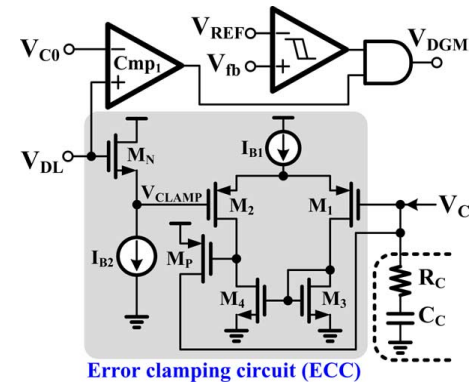

Fig. 17. Schematic of the proposed DGM circuit for ultra-light load condition.

the turning-off operation of the $M_{S 1}$ does not need a large size of $M_{W}$ to disable the power switch $M_{S 1}$ due to the three-stage cascaded current mirrors. Besides, the value of $K_{1}, K_{2}$ and $K$ is design as 10,10 , and 400 , respectively for reasonable consideration of acceptable power loss and frequency response. That is, the power loss consumed by the current-mode driving circuit is only about $0.2775 \%$ of total power and it brings less deterioration of total power efficiency.

\section{Deep-Green Mode (DGM) Operation}

To maintain high power conversion efficiency at ultra-light loads, the DGM circuit as depicted in Fig. 17 can be utilized to mask the switching clocks to reduce switching power loss. When the pre-error signal $V_{C 0}$ is lower than a threshold voltage level $V_{\mathrm{DL}}$, the DGM operation will be activated by triggering the signal $V_{\mathrm{DGM}}$. Thus, the system is operating by ripple-based control and the output voltage is monitored by the hysteresis comparator to guarantee the output voltage regulation. Moreover, the signal $V_{\mathrm{C}}$ is disconnected to EA and clamped at voltage $V_{\mathrm{CLAMP}}$ by the error-clamping circuit (ECC) which is used to structure a feedback loop. The $\mathrm{R}_{\mathrm{C}}$ and the $\mathrm{C}_{\mathrm{C}}$ can be used to increase the circuit stability. The clamped voltage $V_{\text {CLAMP }}$ is defined by the $V_{\mathrm{DL}}$ through the source follower $M_{N}$. The gate-source voltage of $M_{N}$ works as the hysteresis voltage to avoid incorrect toggle between the DGM and the normal operation. Clamping function aims to prevent the cross interference between the linear loop of current driving capability in the normal operation and the ripple-based control in the DGM operation.

\section{EXPRIMENTAL RESULTS}

The proposed SC DC-DC converter with the LFC and DGM techniques was fabricated in $55 \mathrm{~nm}$ CMOS process for SoC integration. The input voltage $V_{\mathrm{IN}}$ ranges from $3.3 \mathrm{~V}$ to 3.6 $\mathrm{V}$. The nominal output voltage is $1 \mathrm{~V}$ to supply the core devices in $55 \mathrm{~nm}$ technology. More importantly, the flying capacitors and the output capacitor can be used as small as $0.1 \mu \mathrm{F}$ and $1 \mu \mathrm{F}$, respectively. The maximum loading current is 250 $\mathrm{mA}$. The design specifications of proposed SC converter are listed in Table II. The chip micrograph with active area of 1100 


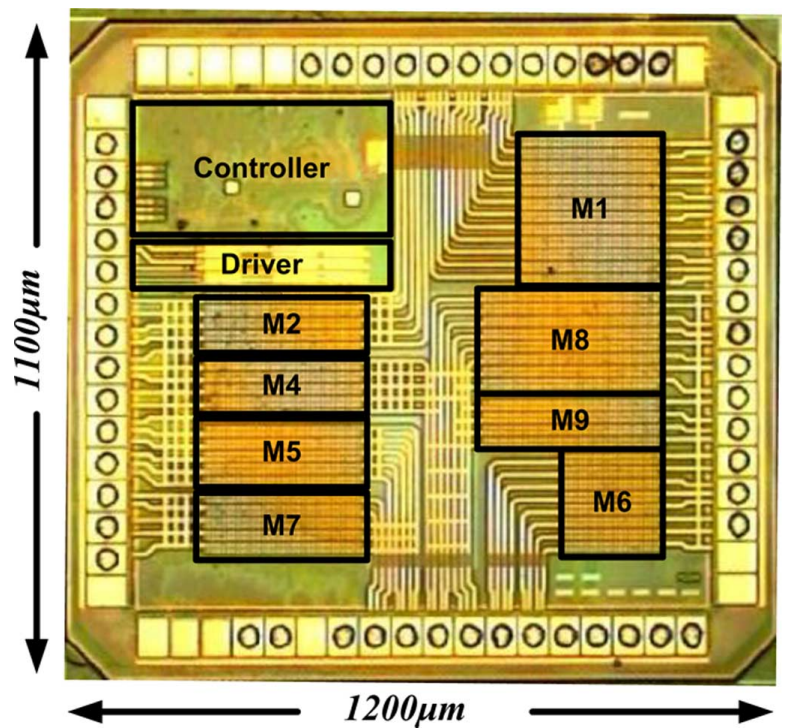

Fig. 18. Chip micrograph of the proposed SC converter.

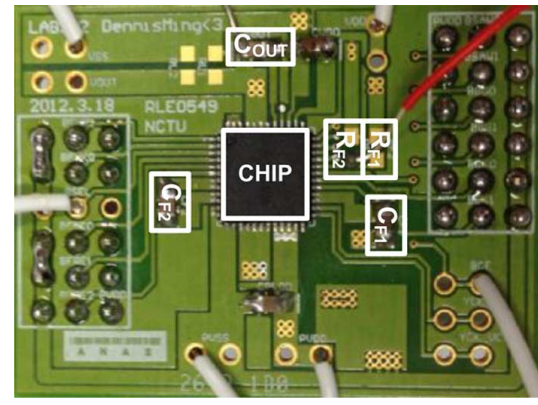

Fig. 19. Prototype of the proposed SC converter.

TABLE II

DESIGN SPECIFICATIONS

\begin{tabular}{|c|c|c|}
\hline Parameter & This work & Unit \\
\hline Technology & 55 & $\mathrm{~nm}$ \\
\hline Input voltage $\left(V_{I N}\right)$ & $3.3-3.6$ & $\mathrm{~V}$ \\
\hline Nominal output voltage $\left(V_{O U T}\right)$ & 1 & $\mathrm{~V}$ \\
\hline Flying capacitor $\left(C_{F I}, C_{F 2}\right)$ & 0.1 & $\mu \mathrm{F}$ \\
\hline Output capacitor $\left(C_{O U T}\right)$ & 1 & $\mu \mathrm{F}$ \\
\hline Maximum load current & 250 & $\mathrm{~mA}$ \\
\hline Loop gain & $<68$ & $\mathrm{~dB}$ \\
\hline Bandwidth & $<150$ & $\mathrm{KHz}$ \\
\hline Line regulation & 3.91 & $\mathrm{mV} / \mathrm{V}$ \\
\hline Load regulation & 0.086 & $\mathrm{mV} / \mathrm{mA}$ \\
\hline Adjustable switching frequency & $0.5,1,2,4$ & $\mathrm{MHz}$ \\
\hline Max. output voltage ripple & $<30$ & $\mathrm{mV}$ \\
\hline Normalized Power conversion efficnecy & $>90$ & $\%$ \\
\hline (10mA-250mA) & & \\
\hline
\end{tabular}

$\mu \mathrm{m} \times 1200 \mu \mathrm{m}$ is shown in Fig. 18. The prototype of the proposed SC converter is shown in Fig. 19. Obviously, with inductor-less architecture of the proposed SC converter, the PCB cost is as less as possible with regardless of the other testing components.

Fig. 20 demonstrates the measured steady-state operation with different switching frequencies under different load conditions when the input and regulated output voltage are $3.3 \mathrm{~V}$ and $1 \mathrm{~V}$, respectively. The $C_{F 1 P}$, which is the positive terminal of the flying capacitor $C_{F 1}$ in Fig. 4, shows the switching frequency is $500 \mathrm{kHz}$ in Fig. 20(a). Due to light load condition, the switching frequency is actually reduced to a smallest value for power saving. The power conversion efficiency is kept higher than $84 \%$. Simultaneously, the output ripple can be

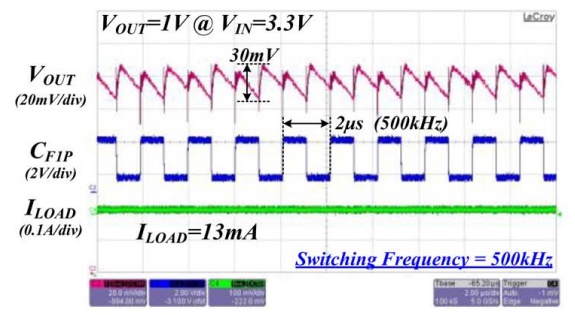

(a)

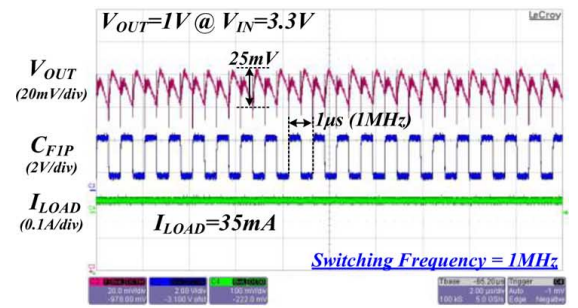

(b)

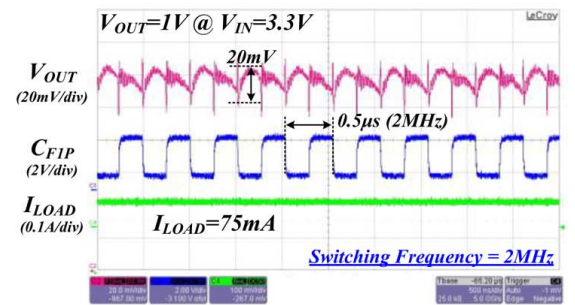

(c)

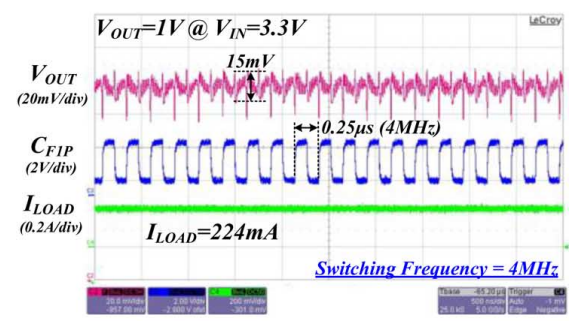

(d)

Fig. 20. Measured steady-state operation with different switching frequencies under different load conditions. (a) $I_{\mathrm{LOAD}}=13 \mathrm{~mA}$. (b) $I_{\mathrm{LOAD}}=35 \mathrm{~mA}$. (c) $I_{\mathrm{LOAD}}=75 \mathrm{~mA}$.(d) $I_{\mathrm{LOAD}}=224 \mathrm{~mA}$

effectively controlled within $30 \mathrm{mV}$. Similarly, Figs. 20(b)-(d) show increasing switching frequency from $1 \mathrm{M}$ to $4 \mathrm{M}$ owing to the increase at loading current from $35 \mathrm{~mA}$ to $224 \mathrm{~mA}$. Furthermore, the output voltage ripple can be kept smaller than $25 \mathrm{mV}$ because the output voltage ripple can be reduced by increasing the switching frequency.

Fig. 21 shows the completely measured load transient response between medium and light loads with distinct switching frequencies. The $C_{F 1 N}$ is the signal of the negative terminal of the flying capacitor $C_{F 1}$ in Fig. 4. When the $I_{\mathrm{LOAD}}$ changes from $70 \mathrm{~mA}$ to $25 \mathrm{~mA}$, the switching frequency is adjusted from $1 \mathrm{MHz}$ to $500 \mathrm{kHz}$ with the output voltage ripples, $25 \mathrm{mV}$ and 30 $\mathrm{mV}$, respectively. The performance can also be maintained when the $I_{\mathrm{LOAD}}$ changes from $25 \mathrm{~mA}$ back to $70 \mathrm{~mA}$. The recovery times of overshoot and undershoot are $5 \mu \mathrm{s}$ and $20 \mu \mathrm{s}$, respectively. Good voltage regulation and fast transient response are achieved because of high loop gain and bandwidth. Fig. 22(a) can demonstrate the details of the LFC technique mechanism. The LFC contains the comparative operation of two clocks, $V_{\mathrm{CK} \_\mathrm{VC}}$ and $V_{C K_{-} R E F}$ to determine the frequency. Fig. 22(b) shows the duty of $V_{\mathrm{CK}_{-} \mathrm{VC}}$ is smaller than that of the $V_{C K_{-} R E F}$ when the $I_{\mathrm{LOAD}}$ steps from $70 \mathrm{~mA}$ to $25 \mathrm{~mA}$, or vice versa in 


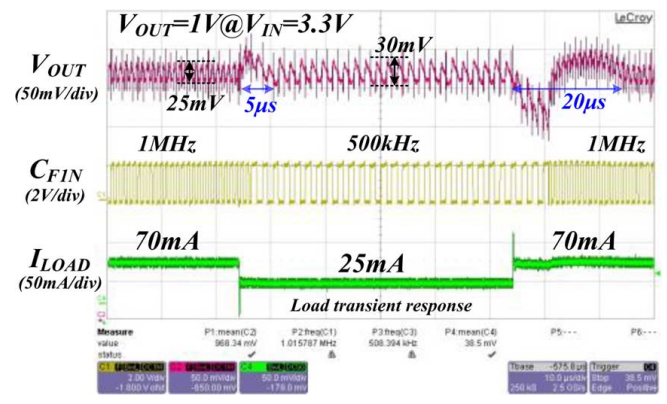

Fig. 21. Measured load transient response between $70 \mathrm{~mA}$ and $25 \mathrm{~mA}$ with adjusted switching frequencies.

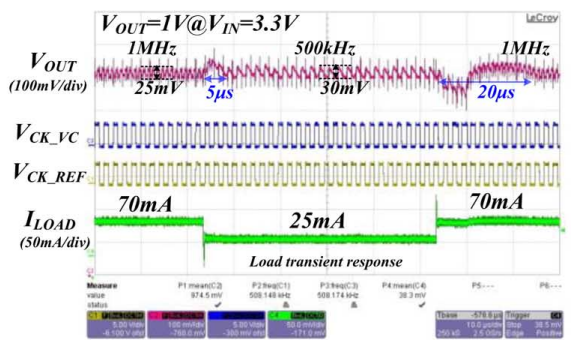

(a)

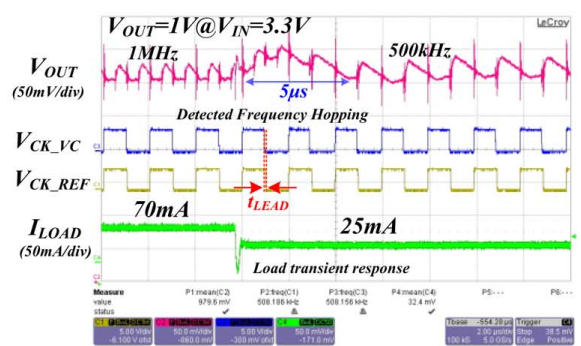

(b)

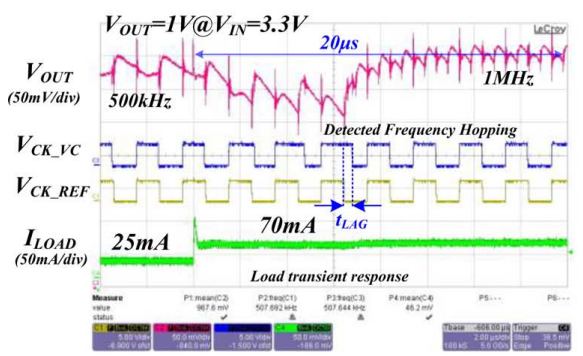

(c)

Fig. 22. Measured load transient response with the LFC techinque. (a) Load transient response from $70 \mathrm{~mA}$ to $25 \mathrm{~mA}$. (b) Load transient response from 70 $\mathrm{mA}$ to $25 \mathrm{~mA}$. (c) Load transient response from $25 \mathrm{~mA}$ to $70 \mathrm{~mA}$.

Fig. 22(c). As expected, the switching frequency changes if the $t_{L A G}$ or the $t_{L E A D}$ is greater than the $t_{T H}$.

The load transient response with both step-up and step-down between middle and heavy loads is depicted in Fig. 23(a). As shown in Figs. 23(b) and (c), the switching frequency will increase or decrease by the LFC technique as $1 \mathrm{MHz}$ and $2 \mathrm{MHz}$ with the loading current of $70 \mathrm{~mA}$ and $130 \mathrm{~mA}$, respectively. The output ripple can be decreased when the switching frequency increases. The recovery time is about $7 \mu \mathrm{s}$ for undershoot and about $12 \mu \mathrm{s}$ for overshoot. Fig. 24 shows the DGM operation for enhancing the ultra-light load efficiency if load current is $10 \mathrm{~mA}$. Meanwhile, the output voltage ripple can be kept within $30 \mathrm{mV}$.

The measured normalized power conversion efficiency and the output ripple with or without the proposed LFC and DGM

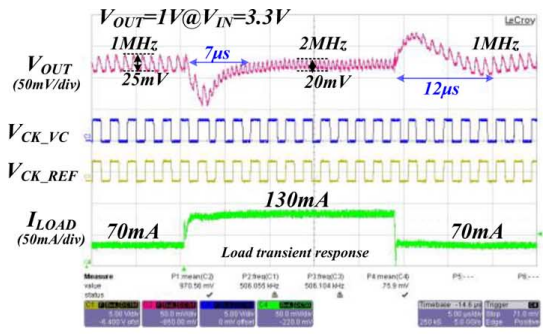

(a)

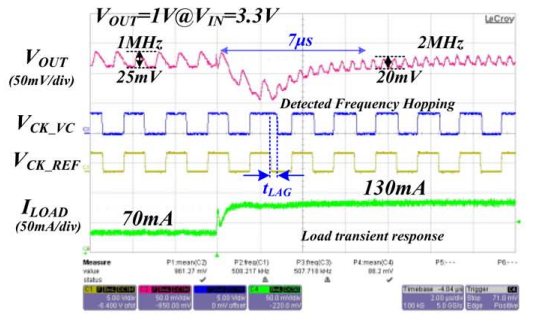

(b)

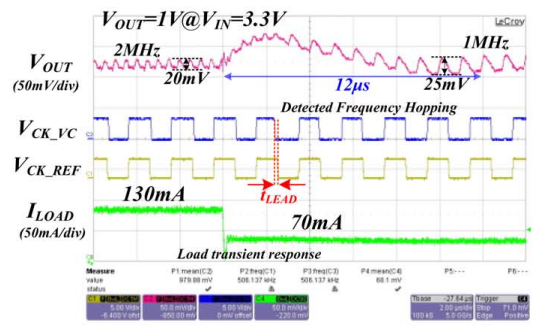

(c)

Fig. 23. Measured load transient response with LFC techinque (a) load transient between $70 \mathrm{~mA}$ to $130 \mathrm{~mA}$ (b) load transient from $70 \mathrm{~mA}$ to $130 \mathrm{~mA}$ (c) load transient from $130 \mathrm{~mA}$ to $70 \mathrm{~mA}$.

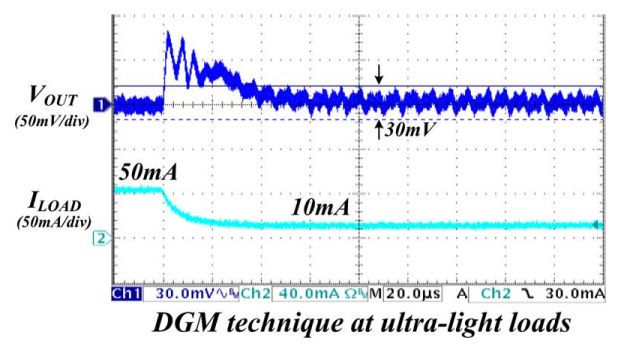

Fig. 24. Measured load transient response from $50 \mathrm{~mA}$ to $10 \mathrm{~mA}$ with the DGM control.

controls are shown in Figs. 25 and 26, respectively. According to (1) with the designed $V_{\mathrm{IN}}$ and $V_{\mathrm{OUT}}$, the ideal efficiency is $91 \%$. The switching loss can be greatly reduced owing to the proposed LFC and DGM controls. The measured peak efficiency increases to $89 \%$, which is equal to $98 \%$ normalized efficiency, when the $I_{\mathrm{LOAD}}$ is $100 \mathrm{~mA}$ and the overall normalized efficiency is maintained higher than $90 \%$ from $10 \mathrm{~mA}$ to $250 \mathrm{~mA}$. The output voltage ripple becomes larger during the light-to-heavy loads change under the operation with a constant switching frequency. That is, the ripple can also be minimized by increasing the switching frequency and guaranteed smaller than $30 \mathrm{mV}$ with smaller flying capacitors and output capacitor compared to the commercial products. Finally, the comparisons of the prior SC methodologies are shown in Table III.

\section{CONCLUSion}

The pseudo-clock controlled LFC SC DC-DC converter with the DGM operation is proposed to achieve high efficiency over a wide load range for power management in SoC applications. 
TABLE III

COMPARISON TABLE WITH THE PRIOR ARTS

\begin{tabular}{|c|c|c|c|c|c|c|}
\hline & This work & JSSC 2007 [8] & ISSCC 2012 [21] & ISSCC 2010 [18] & PE 2011 [22] & TVLSI 2013 [23] \\
\hline Technology & $55 \mathrm{~nm}$ & $0.6 \mu \mathrm{m}$ & $0.18 \mu \mathrm{m}$ & $32 \mathrm{~nm}$ & $\mathrm{~N} / \mathrm{A}$ & $0.5 \mu \mathrm{m}$ \\
\hline Controller methodology & LFC & $\begin{array}{l}\text { Pseudo- } \\
\text { continuous }\end{array}$ & N/A & $\begin{array}{l}2 / 3,1 / 2,1 / 3 \\
\text { step-down }\end{array}$ & $\begin{array}{l}\text { Adaptive Mixed On- } \\
\text { Time and Switching } \\
\text { Frequency Control }\end{array}$ & PFM \\
\hline Input voltage $\left(V_{I N}\right)$ & $3.3-3.6 \mathrm{~V}$ & $1.5 \mathrm{~V}-3.2 \mathrm{~V}$ & $11 \mathrm{~V}$ & $2 \mathrm{~V}$ & $12 \mathrm{~V}$ & $3-4.5 \mathrm{~V}$ \\
\hline Output voltage $\left(V_{\text {OUT }}\right)$ & $1 \mathrm{~V}$ & $2.7 / 3.3 \mathrm{~V}$ & $1.5 \mathrm{~V}$ & $0.88 \mathrm{~V}$ & $9 \mathrm{~V}$ & $5 \mathrm{~V}$ \\
\hline Number of flying capacitor & 2 & 2 & 8 & 2 (per cell) & 8 & 1 \\
\hline Flying capacitor $\left(C_{F 1}, C_{F 2}\right)$ & $0.1 \mu F$ (off-chip) & $1 \mu F$ (off-chip) & $10 \mu F$ (off-chip) & N/A & $47 \mu F$ (off-chip) & $0.33 \mu \mathrm{F}$ (off-chip) \\
\hline Capacitor $\left(C_{\text {out }}\right)$ & $1 \mu F$ (off-chip) & $2.2 \mu \mathrm{F}$ (off-chip) & $110 \mu F$ (off-chip) & $\mathbf{0}$ & $47 \mu F^{*} 4$ (off-chip) & $1 \mu F$ (off-chip) \\
\hline Switching frequency $\left(V_{C K}\right)$ & $500 \mathrm{kHz}-4 \mathrm{MHz}$ & $200 \mathrm{kHz}-500 \mathrm{kHz}$ & $\mathbf{N} / \mathbf{A}$ & $60 \mathrm{MHz}-550 \mathrm{MHz}$ & $20 \mathrm{kHz}-100 \mathrm{kHz}$ & $31.25 \mathrm{kHz}-1 \mathrm{MHz}$ \\
\hline Output voltage ripple & $<30 \mathrm{mV}$ & $\sim 20 \mathrm{mV}$ & $\sim 30 \mathrm{mV}$ & N/A & $\sim 100 \mathrm{mV}$ & $\sim 45 \mathrm{mV}$ \\
\hline $\begin{array}{c}\begin{array}{c}\text { Highest normalized } \\
\text { efficiency }\end{array} \\
\end{array}$ & $98 \%$ & $97 \%$ & $92 \%$ & $0.95 \%$ & N/A & $98 \%$ \\
\hline Load transient $\left(\triangle I_{L O A D}\right)$ & $10 \mathrm{~mA}-250 \mathrm{~mA}$ & $<150 \mathrm{~mA}$ & $<\mathbf{A}$ & $\mathbf{N} / \mathbf{A}$ & $\mathbf{1 A}$ & $20 \mathrm{~mA}$ \\
\hline Recovery time $\left(T_{R}\right)$ & $20 \mu \mathrm{s}$ & $25 \mu \mathrm{s}$ & N/A & $\mathbf{N} / \mathbf{A}$ & $400 \mu \mathrm{s}$ & $112 \mu \mathrm{s}$ \\
\hline Line regulation & $3.91 \mathrm{mV} / \mathrm{V}$ & $8.91 \mathrm{mV} / \mathrm{V}$ & N/A & N/A & $100 \mathrm{mV} / \mathrm{V}$ & $29 \mathrm{mV} / \mathrm{V}$ \\
\hline Load regulation & $0.086 \mathrm{mV} / \mathrm{mA}$ & $0.15 \mathrm{mV} / \mathrm{mA}$ & N/A & $\mathbf{N} / \mathbf{A}$ & $0.1 \mathrm{mV} / 1 \mathrm{~mA}$ & $0.291 \mathrm{mV} / \mathrm{mA}$ \\
\hline $\operatorname{Area}\left(\mathrm{mm}^{2}\right)$ & 1.32 & 5.428 & 11.55 & 0.3782 & N/A & 0.23 \\
\hline
\end{tabular}

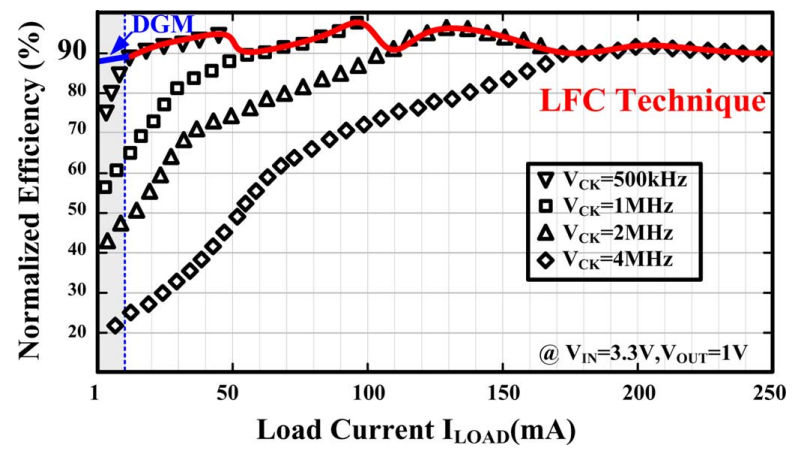

Fig. 25. Measured normalized power conversion efficiency $w / i$ and $w / o$ the proposed LFC and DGM techniques.

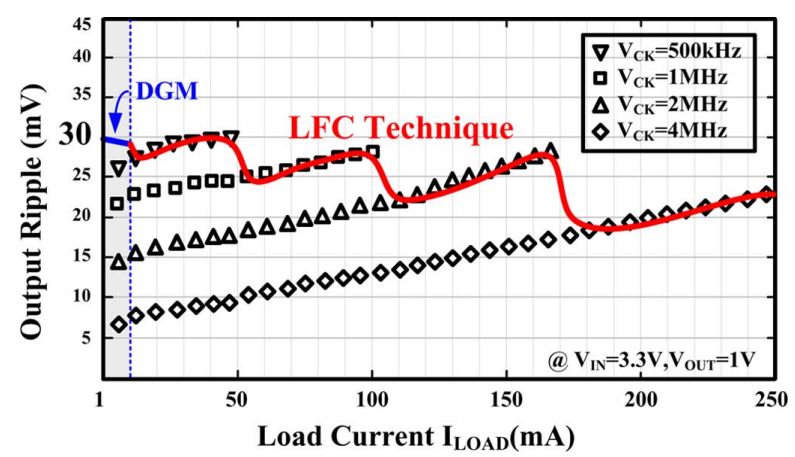

Fig. 26. Measured output voltage ripple $w / i$ and $w / o$ the proposed LFC and DGM techniques.

Besides, small flying capacitors with smaller ESR can be utilized to reduce the switching power loss because the switching frequency can be adjusted according to the load condition. Furthermore, without using the inductor-based power management solution, minimization in PCB area and cost reduction can be achieved. The 1/3X step-down SC operation with the current-mode driving control forms a closed-loop function for modulating the output voltage. In addition, the LFC adjusts the switching frequency according to the distinct load condition which is reflected by PCG to ensure high efficiency and good voltage regulation over a wide load range. The load-dependent frequency can also improve the transient response and is demonstrated in measurement results. Furthermore, the DGM operation further helps enhance the power conversion efficiency at ultra-light loads. Measurement results show the normalized efficiency can be maintained over $90 \%$ and the output voltage ripple can be guaranteed smaller than $30 \mathrm{mV}$.

\section{REFERENCES}

[1] Y.-H. Lee, Y.-Y. Yang, K.-H. Chen, Y.-H. Lin, S.-J. Wang, K.-L. Zheng, P.-F. Chen, C.-Y. Hsieh, Y.-Z. Ke, Y.-K. Chen, and C.-C. Huang, "A DVS embedded power management for high efficiency integrated SoC in UWB system," IEEE J. Solid-State Circuits, vol. 45, no. 11, pp. 2227-2238, Nov. 2010.

[2] C.-C. Wang and J.-C. Wu, "Efficiency improvement in charge pump circuits," IEEE J. Solid-State Circuits, vol. 32, no. 6, pp. 852-860, Jun. 1997.

[3] T. Ying, W.-H. Ki, and M. Chan, "Area-efficient CMOS charge pumps for LCD drivers," IEEE J. Solid-State Circuits, vol. 38, no. 10, pp. 1721-1725, Oct. 2003.

[4] R. Pelliconi, D. Iezzi, A. Baroni, M. Pasotti, and P. L. Rolandi, "Power efficient charge pump in deep submicron standard CMOS technology," IEEE J. Solid-State Circuits, vol. 38, no. 6, pp. 1068-1071, Jun. 2003.

[5] P. Favrat, P. Deval, and M. J. Declercq, "A high-efficiency CMOS voltage doubler," IEEE J. Solid-State Circuits, vol. 33, no. 3, pp. 410-416, Mar. 1998.

[6] H. Lee and P. K. T. Mok, "Switching noise and shoot-through current reduction techniques for switched-capacitor voltage doubler," IEEE $J$. Solid-State Circuits, vol. 40, no. 5, pp. 1136-1146, May 2005.

[7] M.-D. Ker, S.-L. Chen, and C.-S. Tsai, "Design of charge pump circuit with consideration of gate-oxide reliability in low-voltage CMOS processes," IEEE J. Solid-State Circuits, vol. 41, no. 5, pp. 1100-1107, May 2006

[8] H. Lee and P. K. T. Mok, "An SC voltage doubler with pseudo-continuous output regulation using a three-stage switchable opamp," IEEE $J$. Solid-State Circuits, vol. 42, no. 6, pp. 1216-1229, Jun. 2007.

[9] B. R. Gregoire, "A compact switched-capacitor regulated charge pump power supply," IEEE J. Solid-State Circuits, vol. 41, no. 8, pp. 1944-1953, Aug. 2006.

[10] J.-Y. Lee, S.-E. Kim, S.-J. Song, J.-K. Kim, S. Kim, and H.-J. Yoo, "A regulated charge pump with small ripple voltage and fast start-up," IEEE J. Solid-State Circuits, vol. 41, no. 2, pp. 425-432, Feb. 2006. 
[11] F. Su, W.-H. Ki, and C.-Y. Tsui, "Regulated switched-capacitor doubler with interleaving control for continuous output regulation," IEEE J. Solid-State Circuits, vol. 44, no. 4, pp. 1112-1120, Apr. 2009.

[12] M. D. Mulligan, B. Broach, and T. H. Lee, "A 3 MHz low-voltage buck converter with improved light load efficiency," in IEEE ISSCC Dig. Tech. Papers, 2007, pp. 528-620.

[13] B. Sahu and G. A. Rincon-Mora, "An accurate, low-voltage, CMOS switching power supply with adaptive on-time pulse-frequency modulation (PFM) control," IEEE Trans. Circuits Syst. I, Reg. Papers, vol. 54, no. 2, pp. 312-321, Feb. 2007.

[14] H.-W. Huang, C.-C. Chien, K.-H. Chen, and S.-Y. Kuo, "Highly efficient tri-mode control of buck converters with load sensing technique," in Proc. IEEE Power Electron. Specialists Conf., Jun. 2006, pp. 1-4.

[15] L.-K. Chang and C.-H. Hu, "High efficiency MOS charge pumps based on exponential-gain structure with pumping gain increase circuits," IEEE Trans. Power Electron., vol. 21, no. 3, pp. 826-831, May 2006.

[16] Y.-P. Su, Y.-C. Chen, H.-H. Huang, Y.-H. Lee, Y.-Y. Yang, K.-H. Chen, M.-J. Du, and S.-H. Cheng, "Current-mode synthetic control (CSC) technique for high efficiency DC-DC boost converters over a wide load range," in Proc. IEEE Int. Symp. Circuits Syst. (ISCAS), May 2011, pp. 933-936.

[17] Y. K. Ramadass, A. A. Fayed, and A. P. Chandrakasan, "A fully-Integrated switched-capacitor step-down DC-DC converter with digital capacitance modulation in $45 \mathrm{~nm}$ CMOS," IEEE J. Solid-State Circuits, vol. 45, no. 12, pp. 2557-2565, Dec. 2010.

[18] H.-P. Le et al., "A $32 \mathrm{~nm}$ fully integrated reconfigurable switched-capacitor DC-DC converter delivering $0.55 \mathrm{~W} / \mathrm{mm}^{2}$ at $81 \%$ efficiency," in IEEE ISSCC Dig. Tech. Papers, Feb. 2010, pp. 210-211.

[19] X. Zhang and H. Lee, "An efficiency-enhanced auto-reconfigurable 2X/3X SC charge pump for transcutaneous power transmission," IEEE J. Solid-State Circuits, vol. 45, no. 9, pp. 1906-1922, Sep. 2010.

[20] M.-H. Huang, P.-C. Fan, and K.-H. Chen, "Low-ripple and dual-phase charge pump circuit regulated by switched-capacitor-based bandgap refence," IEEE Trans. Power Electron., vol. 24, no. 5, pp. 1161-1172, May 2009.

[21] V. Ng and S. Sanders, "A 92\%-efficiency wide-input-voltage-range switched-capacitor DC-DC converter," in IEEE ISSCC Dig. Tech. Papers, Feb. 2012, pp. 528-620.

[22] S.-C. Tan et al., "Adaptive mixed on-time and switching frequency control of a system of interleaved switched-capacitor converters," IEEE Trans, Power Electron., vol. 26, no. 2, pp. 364-380, Feb. 2011.

[23] H.-K. Kwan, D. C. W. Ng, and V. W. K. So, "Design and analysis of dual-mode digital-control step-up switched-capacitor power converter with pulse-skipping and numerically controlled oscillator-based frequency modulation," IEEE Trans. Very Large Scale Integr. (VLSI) Syst., vol. 21, no. 11, pp. 2132-2140, Nov. 2013.

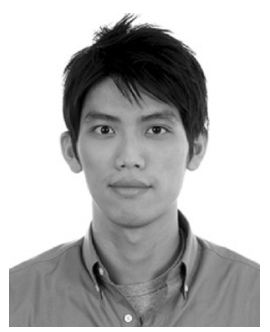

Wei-Chung Chen (S'12) was born in Yunlin, Taiwan. He received the B.S. degree from the Department of Electrical Engineering, National Sun Yat-sen University in 2010, and M.S. degree from National Chiao Tung University in 2012. He is currently pursuing the Ph.D. degree in the Institute of Electrical and Computer Engineering, National Chiao Tung University, Hsinchu, Taiwan.

$\mathrm{He}$ is a member of the Mixed-Signal and Power Management IC Laboratory, Institute of Electrical and Computer Engineering, National Chiao Tung University, Hsinchu, Taiwan. His research interests include the power management IC design, analog integrated circuits, and mixed signal IC design.

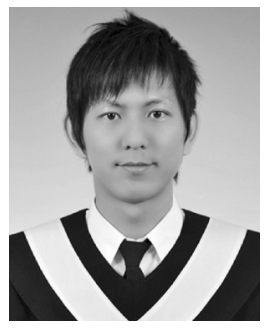

Da-Long Ming was born in Namhsan, Myanmar. He received the B.S. degree from the Department of Electrical Engineering, National Cheng Kung University, Tainan, Taiwan, in 2010, and the M.S. degree from the Department of Electrical Engineering, National Chiao Tung University, Hsinchu, Taiwan, in 2012.

He is a member of the Mixed Signal and Power Management IC Laboratory at National Chiao Tung University. His research interests include the power management IC design, the LED driver IC design and mixed-signal IC design. He is currently a Senior Engineer at Himax Technologies, Inc, Taiwan where he is engaged in designing driver IC.

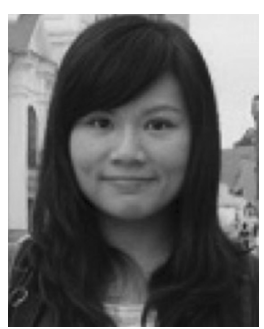

Yi-Ping Su was born in Taipei, Taiwan. She received the B.S. degree from the Department of Electrical Engineering, National Sun Yat-Sen University, Kaohsiung, Taiwan, in 2009. She is currently working toward the Ph.D. degree at the Institute of Electrical Engineering, National Chiao Tung University, Hsinchu, Taiwan.

She is a Member in the Mixed Signal and Power Management IC Laboratory, Institute of Electrical Engineering, National Chiao Tung University. Her current research interests include the power management and analog integrated circuits design.

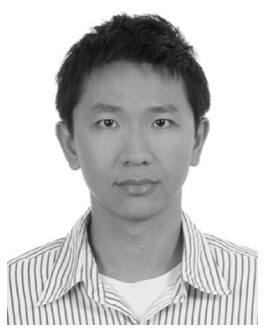

Yu-Huei Lee (S'09) was born in Taipei, Taiwan. He received the B.S. and M.S. degrees from the Department of Electrical and Control Engineering, National Chiao Tung University, Hsinchu, Taiwan, in 2007 and 2009, respectively, and the Ph.D. degree from the Institute of Electrical Control Engineering, National Chiao Tung University, Hsinchu, Taiwan, in 2012 .

$\mathrm{He}$ is a member at the Mixed Signal and Power IC Laboratory, Institute of Electrical Control Engineering, National Chiao Tung University, Hsinchu, Taiwan. His current research interests include the power management integrated circuit design, light-emitting diode driver IC design, and analog integrated circuits.

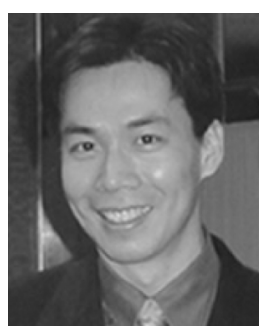

Ke-Horng Chen (M'04-SM'09) received the B.S., M.S., and Ph.D. degrees in electrical engineering from National Taiwan University, Taipei, in 1994, 1996, and 2003, respectively.

From 1996 to 1998, he was a part-time IC Designer at Philips, Taipei, Taiwan. From 1998 to 2000, he was an Application Engineer at Avanti, Ltd., Taiwan. From 2000 to 2003, he was a Project Manager at ACARD, Ltd., where he was engaged in designing power management ICs. He is currently a Director of the Institute of Electrical Control Engineering and a Professor of the Department of Electrical Engineering, National Chiao Tung University, Hsinchu, Taiwan, where he organized a Mixed-Signal and Power Management IC Laboratory. He is the author or coauthor of more than 100 papers published in journals and conferences, and also holds several patents. His current research interests include power management ICs, mixed-signal circuit designs, display algorithm and driver designs of liquid crystal display (LCD) TV, red, green, and blue (RGB) color sequential backlight designs.

Dr. Chen has served as an Associate Editor of the IEEE TRANSACTIONS ON POWER ELECTRONICS and IEEE TRANSACTIONS ON CIRCUITS AND SYSTEMS-PART II: EXPRESS BRIEFS. He also joined Editorial Board of Analog Integrated Circuits and Signal Processing in 2013. He is on the IEEE Circuits and Systems (CAS) VLSI Systems and Applications Technical Committee, and the IEEE CAS Power and Energy Circuits and Systems Technical Committee. $\mathrm{He}$ is on the Society for Information Display (SID) and International Display Manufacturing Conference (IDMC) Technical Program Sub-committees. He is the Tutorial Co-Chair of IEEE Asia Pacific Conference on Circuits and Systems (2012 APCCAS). He is the Task Chair of Integrated Power Electronics of IEEE International Conference on Power Electronics and Drive Systems (PEDS) 2013. He is a Technical Program Co-Chair of IEEE International Future Energy Electronics Conference (IFEEC) 2013. 